\title{
POSITIVE PSYCHOLOGY AND FIBROMYALGIA
}

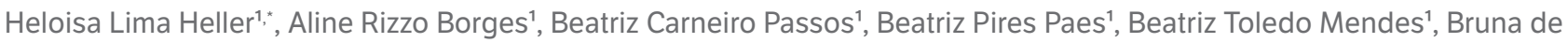
Paula Gonçalves Lyra', Ciro Moisés Oliveira Vieira dos Santos', Gabriela Furlan Ribeiro Barbosa Netto², Gustavo Araújo do Nascimento Santos', João Pedro de Oliveira Aucelio', Luis Otavio Amarante Franco', Marcos Igor Albanaz Vargas', Maria Luiza Pimentel de Oliveira', Matheus Macêdo da Silva', Maurício Silva de Jesus', Mirella Bastos Sales', Natália Vargas do Nascimento ${ }^{2}$, Paulo Ricardo Guimaraes Rocha Storni ${ }^{3}$, Rebeca Naoum Lorga', Tamires Martinelli de Oliveira Ferraz', Viviane Cristina Uliana Peterle, Ana Paula Gomides ${ }^{1}$

1. Centro Universitário de Brasília, Brasília (DF), Brazil. 2. Universidade Católica de Brasília, Brasília (DF), Brazil. 3.Centro Universitário Euro-Americano, Brasília (DF), Brazil.

*Corresponding author: heloheller98@gmail.com

\section{BACKGROUND}

Fibromyalgia is a condition that causes widespread pain and is highly correlated with psychiatric disorders. Due to unsatisfactory results of pharmacological treatment alone, alternative therapies may be involved in the management of fibromyalgia symptoms. Studies have shown excellent outcomes with positive psychology and cognitive behavioral therapy in taming pain and psychological distress. Positive psychology aims to increase well-being, reduce the impact of pain, minimizing associations between pain and negative symptoms, such as depression and insomnia.

\section{MATERIALS AND METHODS}

A systematic literature review was undertaken. The terms "Fibromyalgia", "Positive Psychology" and "Cognitive Behavioral Therapy" and their synonyms were used in searches in the PubMed, Cochrane Library (including Embase, Ct.gov, ICTRP, CINAHL), LILACS, IBECS, CRD and Epistemonikos databases.

\section{RESULTS}

A total of 1138 articles were established. After 121 duplicates were removed, and title and summary readings between peers, a total of 107 articles were selected for reading, of which 48 are part of this review. Many studies have found elevated rates of trauma, victimization, interpersonal conflict among people with fibromyalgia, especially within patients actively seeking treatment. In addition to this, observations show that the majority of patients acknowledge that stress aggravates fibromyalgia symptoms. Articles found in this review demonstrated that cognitive-behavioral therapy (CBT) was superior in reducing the severity of fibromyalgia, when compared to pharmacological, combined and absence of treatment. Significant reduction in pain, fatigue, and sleeplessness, improved function, mood state and general health after an 8-week intervention of weekly sessions of a CBT approach were documented. The reduction in pain with CBT is correlated to the depletion of the nociceptive response compared to usual treatment, in addition to depression rates and better mental health scores, when compared to the control group. It was also demonstrated that doses of weekly pain control medications were significantly lower in patients undergoing occupational cognitive therapy. Cognitive-behavioral therapy and operant-behavioral therapy have shown to have the highest effect for pain reduction among other psychological techniques, including relaxation, hypnotherapy and writing interventions.

\section{CONCLUSION}

Cognitive behavioral therapy can have a positive impact on the treatment of fibromyalgia, reducing the use of medications and promoting a better quality of life. 